\title{
Potential Roles of Climate Feedback, Ocean Vertical Mixing and Overturning Circulation in Mitigating Global Warming
}

Haijun Yang ( $\square$ yanghj@fudan.edu.cn )

Fudan University https://orcid.org/0000-0002-2962-8980

Qiangzi Yang

Peking University

Yang Li

Peking University

Xiangying Zhou

Fudan University

\section{Research Article}

Keywords: Global warming, Warming hiatus, Climate feedback, Vertical mixing, Overturning circulation

Posted Date: September 13th, 2021

DOI: https://doi.org/10.21203/rs.3.rs-861080/v1

License: (c) (i) This work is licensed under a Creative Commons Attribution 4.0 International License. Read Full License 


\title{
Potential Roles of Climate Feedback, Ocean Vertical Mixing and Overturning Circulation in Mitigating Global Warming
}

\author{
Haijun Yang*1 ${ }^{* 1}$ Qianzi Yang ${ }^{2}$, Yang $\mathrm{Li}^{2}$, and Xiangying Zhou ${ }^{1}$ \\ ${ }^{I}$ Department of Atmospheric and Oceanic Sciences and Institute of Atmospheric Science and CMA- \\ FDU Joint Laboratory of Marine Meteorology, Fudan University, Shanghai, 200438, China. \\ ${ }^{2}$ Department of Atmospheric and Oceanic Sciences, School of Physics, Peking University, Beijing, \\ 100871, China
}

(1)

10

*Corresponding author address: Haijun Yang, Department of Atmospheric and Oceanic

Sciences, Fudan University, 2005 Songhu Road, Shanghai China, 200438.

Email: yanghj@fudan.edu.cn. 
Despite the rapid increase of greenhouse gases (GHGs) in the atmosphere during the past 50 years, observed global mean surface temperature (GMST) showed a pause in the warming trend during the first decade of the twenty-first century. This is referred to as the global warming "hiatus." A dominant hypothesis emphasizes that the superimposition of the cold phase of the Pacific decadal variability and the global warming trend can lead to the hiatus. This also implies a future acceleration of global warming once the Pacific decadal variability enters its warm phase. Using simply energy balance model, we explore three potential mechanisms that may restrain the GMST warming trend: enhanced negative climate feedback, downward ocean vertical mixing and overturning circulation. Forced by linearly increasing heating, a stronger negative climate feedback can reduce the GMST warming rate, but cannot result in a warming hiatus. Although the global overall climate feedback can be assumed to be more negative theoretically, in reality this feedback is likely to become more positive, which would potentially result in a disastrous runaway climate in several decades. Enhanced downward mixing of heat can cause a short-lived hiatus of surface warming rate, but this would eventually accelerate the surface warming in the long run. A stronger overturning circulation can transport more surface warm water downward just temporarily, which cannot stop the warming trend. This study suggests that in the long run, the only route to contain the global warming effectively is to reduce the GHGs.

Keywords: Global warming; Warming hiatus; Climate feedback; Vertical mixing; Overturning circulation 
1. Introduction

The increase of greenhouse gases (GHGs) in the atmosphere is commonly thought as the deterministic cause for the centennial warming trend of the global mean surface temperature (GMST) since the Industrial Revolution (IPCC 2013). However, regardless the steep increase of the carbon dioxide $\left(\mathrm{CO}_{2}\right)$ in the atmosphere since 1960, the GMST showed a warming pause for about 10 years during the first decade of the twentieth-one century (Fig. 1) (Easterling and Wehner 2009; Knight et al. 2009; Trenberth and Fasullo 2013). This phenomenon is termed as the global warming "hiatus" (IPCC 2013; Kosaka and Xie 2013; Yan et al. 2016). The observed $\mathrm{CO}_{2}$ concentration at Mauna Loa of Hawaii has exceeded 400 ppm since 2015 (Fig. 1), with the growth rate of annual mean $\mathrm{CO}_{2}$ at Mauna Loa being about 2 ppm/year since 2000, well above any preceding period. This inconsistency between the warming hiatus and the intensification of anthropogenic forcing has set off fierce scientific and political debates on the facticity of global warming.

A global warming hiatus can appear when the warming trend encounter the natural climate variability. This mechanism was first proposed by Kosaka and Xie (2013), and thereafter recognized by many scientists (Clement and DiNezio 2014; England et al. 2014; Dai et al. 2015). In Kosaka and Xie (2013), the global warming hiatus is well simulated after nudging the model sea surface temperature (SST) to the observed SST in the central to eastern tropical Pacific in a historical run. Xie et al. (2016) further indicated that the time variation of SST can be driven by radiative forcing and a periodic natural variability. When the natural variability happens to be in the downward phase, the warming hiatus would occur. The natural variability is widely believed to be the Pacific Decadal Oscillation (PDO) (Clement and DiNezio 2014; Dai et al. 2015). The recent hiatus appeared because the historical SST happened to be in the cold phase of the PDO during the first decadal of the 21th century (Meehl et al. 2013; Trenberth and Fasullo 2013; Brown et al. 2015). This kind of hiatus also 

occurred from 1943 to 1976 (Fig. 1) (Trenberth and Fasullo 2013; England et al. 2014), when the PDO was in its cold phase. In summary, the cold SST anomaly in the tropical Pacific can temporarily restrain the global warming trend, leading to a GMST warming hiatus. An implication is that the future acceleration of global warming appears to be inevitable once the warm phase of the PDO returns.

Some studies also noted that the cold SST anomaly in the tropical Pacific may not be related to the cold phase of the PDO. It may simply due to the intensification of the trade wind in the tropical Pacific, which sets up the La Nina-type SST pattern in the eastern Pacific (England et al. 2014). The intensified trade wind drives warm surface water from the western Pacific into the Indian Ocean through the strengthened Indonesian Throughflow (ITF) (Liu et al. 2016); thus, more heat would be sequestered in the subsurface of the Indian Ocean. The horizontal energy exchanges between the Pacific and Indian oceans in the upper $300 \mathrm{~m}$ is also an alternative argument for the GMST hiatus (Lee et al. 2015; Nieves et al. 2015; Liu et al. 2016).

A more intuitive explanation to the recent GMST hiatus comes from the view of the Earth's energy budget - either a reduction of radiative forcing from the top of atmosphere (TOA) or an enhanced heat uptake by the deeper ocean (Tung and Chen 2018). Weakened solar radiation during a period of low sunspot activity (Trenberth 2009), or due to reduction in stratospheric water vapour (Solomon et al. 2010), and the increasing aerosols related to anthropogenic activities (Kaufmann et al. 2011) and 17 small volcano eruptions since 1999 (Santer et al. 2014) could have contributed to the recent hiatus by weakening the net TOA incoming energy. Trenberth and Fasullo (2013) showed that forcing reductions from these factors likely contribute no more than $20 \%$ of the global warming slowdown. Schmidt et al. (2014) showed that recent moderate volcano eruptions and anthropogenic pollutions account for half of the divergence between observation and model simulations, while the 
solar minimum explains one seventh. Kühn et al. (2014) found that Asian pollution from coal burning has very little effect globally or regionally, because of the cancelation between the warming effect of black carbon and the cooling effect of sulphate aerosols.

During the recent hiatus, the net TOA energy gain is estimated to be $0.5 \pm 0.43 \mathrm{~W} / \mathrm{m}^{2}$ (Loeb et al. 2012), showing no apparent reduction. The deep ocean is thus emerged as a likely candidate to reserve the additional energy, buffering the global warming and leading to the GMST hiatus (Meehl et al. 2011; Balmaseda et al. 2013a, b; Rhein et al. 2013; Liu et al. 2016). Both observations and model simulations show that the vertical heat redistribution, especially in the North Atlantic and Southern Ocean, is remarkably different between hiatus period and fast-warming period (Meehl et al. 2011; Chen and Tung 2014; Liu et al. 2016). The subsurface warming in the Southern Ocean is attributed to the southward displacement and intensification of the circumpolar jet, while the North Atlantic's role is believed to be related to the Atlantic meridional overturning circulation (AMOC). Meehl et al. (2011) simulated a negative trend of the AMOC in a historical run, that is, a weakening of deep convection in the North Atlantic, which can lead to a subsurface warming. In contrast, Chen and Tung (2018) showed an acceleration of the AMOC during 1993-2005 based on various independent proxies. They believed that the enhanced deep convection transports more heat downward to the deep ocean, which neutralizes the warming effect caused by human activities and slows down the surface warming.

The debates over the global warming hiatus involve three issues: Did the hiatus truly happen? Which part of the ocean contributed the most to the hiatus? Can the Earth surplus energy entering the deeper ocean eventually lead to the hiatus? The first question emerged in recent years because some latest reanalysis data do not show hiatus at all (Lewandowsky et al. 2015). These debates also suggest that we are still far from fully understanding the cause and mechanisms of the hiatus. Given the steep 
linear increase of the GHGs' forcing, the transient change of Earth's climate system is much more complex than what researchers thought.

This work does not address the three questions mentioned above. Instead, we try to explore theoretically whether the Earth's climate as a whole would exhibit a "hiatus" under a linear increase of the GHGs. Using simple energy balance models (EBMs), we examine three candidates: the overall global climate feedback, ocean vertical mixing and ocean overturning circulation. From the viewpoint of Earth energy balance, a stronger negative climate feedback would reduce the net energy absorbed by the Earth, which might have potential to result in a GMST hiatus. However, the global climate feedback is getting even positively stronger (Armour et al. 2013; Gregory et al. 2015; Rugenstein et al. 2020), which would potentially result in a disastrous runaway climate. Enhanced ocean vertical mixing can cause a short-lived surface warming hiatus, by storing more heat in the deeper ocean; however, it would eventually accelerate the surface warming in the long run, once the deeper ocean starts to release heat upward. A stronger overturning circulation can also transport more surface warm water downward, contributing to the hiatus over a short time. However, the overturning circulation itself depends strongly on the stratification, which can be shut down by the reduced stratification. This study suggests that in the long run, the only route to contain the global warming effectively is to reduce the greenhouse gases, namely, to change the behaviour of human beings.

This paper is organized as follows. In Section 2, we introduce the one-box EBMs and the role of climate feedback in the global warming hiatus is investigated. Two-box and 4-box models are introduced in Section 3 and 4, and roles of vertical mixing and ocean overturning circulation are examined, respectively. Summary and discussion are given in Section 5. 


\section{One-box model with climate feedback}

First, we use a zero-dimensional EBM, i.e., a 1-box ocean model, to investigate the impact of climate feedback on surface warming trend (Fig. 2a). The transient response of the GMST in the 1box model is proportional to the net energy flux at the TOA (Gregory et al. 2004), that is

$$
C \frac{d \Delta T}{d t}=F-B \Delta T,
$$

where $C=\rho c_{p} D$ is ocean heat capacity, $\rho$ is seawater density, $c_{p}$ is the seawater specific heat at constant pressure, and $D$ is ocean depth, set to $400 \mathrm{~m}$ here. Symbol $\Delta$ denotes the anomaly from the equilibrium climate. $F$ is the anomalous radiative forcing at the TOA, caused by change of GHGs. $B$ is the climate feedback parameter for the Earth as a whole. In this paper, positive (negative) $B$ denotes negative (positive) feedback. $B$ must be positive so that the system can reach a stable state. Bloch-Johnson et al. (2015) estimated that the reasonable range of $B$ is $\sim 0.8-1.8 \mathrm{~W} / \mathrm{m}^{2} / \mathrm{K}$, based on the abrupt $4 \times \mathrm{CO} 2$ experiments of the Coupled Model Inter-comparison Project Phase 5 (CMIP5).

Usually, $F$ should be zero in an equilibrium climate state, and temperature stays unchanged. However, if the GHGs increase, the Earth gains extra energy that causes $\Delta T$ to increase. Here, we assume the concentration of GHGs increases linearly with time, and the anomalous radiative forcing can be simply expressed by:

where $\varepsilon$ is set to $0.016 \mathrm{Wm}^{-2} \mathrm{yr}^{-1}$, which is equivalent to the greenhouse effect by a gradual doubling of $\mathrm{CO}_{2}$ concentration over 200 years. The temporal change of the radiative forcing is shown in Fig. 3. 
$159 \frac{\varepsilon}{B}$, that is,

$$
T=\frac{\varepsilon}{B}\left(t-\frac{C}{B}\right) \rightarrow \infty, \quad \frac{d T}{d t}=\frac{\varepsilon}{B}, \quad \text { when } t \rightarrow \infty
$$$$
T=\frac{\varepsilon}{B}\left[t-\frac{C}{B}\left(1-e^{-\frac{B}{C} t}\right)\right]
$$

For simplicity, all $\Delta T$ is written as $T$ from now on. The warming rate is thus,

$$
\frac{d T}{d t}=\frac{\varepsilon}{B}\left(1-e^{-\frac{B}{C} t}\right)
$$

When $t \rightarrow \infty$, the ocean warming goes toward infinity and the warming rate reaches a constant

Figures $4 \mathrm{a}$ and $\mathrm{b}$ show the theoretical solutions of $T$ and $\frac{d T}{d t}$. $T$ increases roughly linearly as expected (Fig. 4a). During the first several years, the warming rate $\left(\frac{d T}{d t}\right)$ itself increases roughly linearly, and then reaches a constant value in about 30-40 years (Fig. 4b). This fast transient timescale is given roughly by $\frac{C}{B}$ (Hansen et al. 1981). In this situation, ocean warming eventually increases linearly (Fig. 4a), and the system will never reach an equilibrium. Of course, stronger negative 
feedback will lead to a weaker warming rate, and vice versa (colour curves, Figs. 4a-b). The

temperature change is straightforward under the constant climate feedback. One important implication here is that, to bend the warming rate curve downward, i.e., to reduce the warming rate to zero, or in other words, to realize a global warming hiatus in this simple box model, a very strong negative feedback is required, to accompany the increasing temperature. In fact, Eq. (5) suggests that only when $B \rightarrow \infty, \frac{d T}{d t}=\frac{\varepsilon}{B} \rightarrow 0$. This situation is practically impossible.

\subsection{Varying climate feedback}

Here, we explore the possibility of a global warming hiatus by assuming a temperaturedependent climate feedback,

$$
B=B_{0}+\alpha T,
$$

where $B_{0}$ is the reference climate feedback from an unperturbed state, and $\alpha$ represents climate feedback changing rate (units: $\mathrm{W} / \mathrm{m}^{2} / \mathrm{K}^{2}$ ). A positive (negative) $\alpha$ means that the climate feedback can become more negative (positive) with global warming. Since Eq. (1) is quadratic, the curves for warming $(T)$ and warming rate $\left(\frac{d T}{d t}\right)$ can be bent downward under strong positive $\alpha$. This situation was studied previously (e.g., Winton et al. 2010; Armour et al. 2013; Bloch-Johnson et al. 2015; Gregory et al. 2015).

The theoretical solution to system (1), (2) and (6) is written as follows,

$$
T(t)=\frac{a \varepsilon m\left[A(1, M)+\frac{K_{1}}{K_{2}} A(3, M)\right]-\frac{b}{2}\left[A(0, M)+\frac{K_{1}}{K_{2}} A(2, M)\right]}{a A(0, M)+\frac{K_{1}}{K_{2}} A(2, M)},
$$


where $M=\frac{b^{2} m}{4}+a \varepsilon t$, and $A(i, M)$ is the Airy function (Abramowitz and Stegun 1964). There are four kinds of Airy function. $A(1, M)$ is the derivative of $A(0, M)$, and $A(3, M)$ is the derivative of $A(2, M)$. The other parameters are defined as follows,

Here,

$$
\begin{gathered}
a=\frac{\alpha}{C}, \quad b=\frac{B_{0}}{C}, \quad K=\frac{\varepsilon}{C}, \quad m=(a K)^{-\frac{2}{3},} \\
K_{1}=\frac{b}{2} A\left(0, \frac{b^{2} m}{4}\right)-a \varepsilon m A\left(1, \frac{b^{2} m}{4}\right), \\
K_{2}=-\frac{b}{2} A\left(2, \frac{b^{2} m}{4}\right)+a \varepsilon m A\left(3, \frac{b^{2} m}{4}\right) .
\end{gathered}
$$

Therefore,

$$
\begin{cases}A(0, M)=0, & A(1, M)=0 \\ A(2, M)=\frac{e^{\frac{2}{3} t^{\frac{3}{2}}}}{\pi^{\frac{1}{2}} t^{\frac{1}{4}}}, & A(3, M)=A(2, M)^{\prime}, \quad \text { when } t \rightarrow \infty .\end{cases}
$$

Figures $4 \mathrm{c}$ and $\mathrm{d}$ show the results from the theoretical solution (7). The global warming will slow down and the warming rate will reduce substantially if the negative climate feedback increases with the global warming (i.e., $\alpha>0$ ) (red curves, Figs. 4c, d). However, a global warming hiatus, i.e., the zero warming rate, appears to be unlikely for a reasonable range of the climate feedback. In contrast, the global warming will be easily out of control if the negative feedback becomes weakened with the global warming (i.e., $\alpha<0$ ) (blue curves, Figs. $4 \mathrm{c}, \mathrm{d}$ ). This is also called "quadratic runaway" (Bloch-Johnson et al. 2015). To view the temperature change more clearly, we examine the situations with $\alpha= \pm 0.5, \pm 1.0 \mathrm{~W} / \mathrm{m}^{2} / \mathrm{K}^{2}$; these values are extremely strong when compared to more practical values derived from observations and coupled models. For example, based on estimates 
from various coupled model studies, $\alpha$ is suggested to be in the range of $\pm 0.06 \mathrm{~W} / \mathrm{m}^{2} / \mathrm{K}^{2}$ (Roe and Armour 2011). Previous studies suggested that the Planck feedback would become more negative under the global warming, at a rate of about $0.02 \mathrm{~W} / \mathrm{m}^{2} / \mathrm{K}^{2}$ (Bloch-Johnson et al. 2015). The water vapour feedback would become more positive, possibly offsetting the negative lapse rate feedback (Bony et al. 2006; Soden and Held 2006). The surface albedo feedback would be weakened with the melting of snow and ice under global warming, that is, this negative feedback will, in fact, become weaker, at a rate of about $0.1 \mathrm{~W} / \mathrm{m}^{2} / \mathrm{K}^{2}$ (Manabe and Bryan 1985).

It is commonly recognized that the climate feedback modulates the equilibrium temperature of the Earth. This simple 1-box EBM suggests that it is unlikely to obtain a global warming hiatus by merely enhancing the negative feedback, in the case of linearly increasing of the external forcing. We can expect a substantial slowdown of the global warming under strong negative feedback, but never the zero warming rate (hiatus). Moreover, even under an unrealistically strong negative feedback, the mitigation effect from climate feedback is not instant. It works slowly at inter-decadal to centennial timescales (Fig. 4). It is unlikely that the climate feedback change has contributed seriously to the GMST hiatus observed in the first decade of the 21 th century.

\section{Two-box model with vertical heat mixing}

As the 1-box EBM does not take into account ocean interior process, we need a 2-box (i.e., 2layer) EBM to study the effect of vertical processes on the surface warming (Fig. 2b). Due to its enormous capacity, the interior ocean should play a role in the GMST hiatus, by taking up heat from the above and redistributing the heat in the vertical (Gregory 2000). The 2-layer box model is widely used in the study of transient climate responses (e.g., Held et al. 2010; Geoffroy et al. 2013; Zhou and 
Chen 2015; Yoshimori et al. 2016), climate sensitivities (Gregory et al. 2015), and so on. The model is effective in capturing the minimal physics of transient surface temperature change (Gregory et al. 2015).

The 2-layer model consists of the upper and lower oceans (Fig. 2b), and the layers have heat capacities $C_{1}$ and $C_{2}$, respectively. Here, we set $C_{2}=10 C_{1}$, corresponding to 400 and $4000 \mathrm{~m}$ thickness, respectively. The upper ocean participates in the surface energy budget, and transports a heat flux $H=\gamma\left(T_{1}-T_{2}\right)$ downward to the deep ocean through processes such as vertical advection, mixing and diffusion; we simply call them "vertical heat transports" The model formula are,

$$
C_{1} \frac{d T_{1}}{d t}=F-B T_{1}-\gamma\left(T_{1}-T_{2}\right)
$$

where $T_{1}$ and $T_{2}$ are the temperature anomalies of upper and lower layers, respectively, from an unperturbed climate; and $T_{v}$ is the change in vertical temperature gradient. $\gamma$ represents the efficiency of vertical heat transport. It is also treated as the heat uptake efficiency by the deep ocean (Gregory and Mitchell 1997; Gregory et al. 2015). $\gamma$ can vary empirically over time (Raper et al. 2002). Watanabe et al. (2013) reported a range of $\gamma$ of about $0.5-1.5 \mathrm{~W} / \mathrm{m}^{2} / \mathrm{K}$ based on data from 16 CMIP5 models. Gregory et al. (2015) used $\gamma$ of about $0.4-0.8 \mathrm{~W} / \mathrm{m}^{2} / \mathrm{K}$ in their box models.

\subsection{Constant efficiency of vertical heat transport}


follows,

251

$$
\begin{gathered}
T_{1}(t)=\frac{\varepsilon}{B}\left[t-\tau_{f} a_{f}\left(1-e^{-\frac{t}{\tau_{f}}}\right)-\tau_{s} a_{s}\left(1-e^{-\frac{t}{\tau_{s}}}\right)\right], \\
T_{2}(t)=\frac{\varepsilon}{B}\left[t-\varphi_{f} \tau_{f} a_{f}\left(1-e^{-\frac{t}{\tau_{f}}}\right)-\varphi_{s} \tau_{s} a_{s}\left(1-e^{-\frac{t}{\tau_{s}}}\right)\right],
\end{gathered}
$$$$
T_{v}(t)=T_{1}-T_{2}=\frac{\varepsilon}{B}\left[\left(\varphi_{f}-1\right) \tau_{f} a_{f}\left(1-e^{-\frac{t}{\tau_{f}}}\right)+\left(\varphi_{s}-1\right) \tau_{s} a_{s}\left(1-e^{-\frac{t}{\tau_{s}}}\right)\right] .
$$

The warming rates for the 2-layer ocean are,

Here, we have defined the following parameters,

$$
b=\frac{B+\gamma}{C_{1}}+\frac{\gamma}{C_{2}}, \quad b^{*}=\frac{B+\gamma}{C_{1}}-\frac{\gamma}{C_{2}}, \quad \delta=b^{2}-4 \frac{B \gamma}{C_{1} C_{2}} .
$$

And the fast transient timescale $\tau_{f}$ and two other "fast" parameters are,

$$
\tau_{f}=\frac{C_{1} C_{2}}{2 B \gamma}(b-\sqrt{\delta}), \quad a_{f}=\frac{\varphi_{s} \tau_{f}}{C_{1}\left(\varphi_{s}-\varphi_{f}\right)} B, \quad \varphi_{f}=\frac{C_{1}}{2 \gamma}\left(b^{*}-\sqrt{\delta}\right) .
$$

The slow timescale $\tau_{s}$ and two other "slow" parameters are,

$$
\tau_{s}=\frac{C_{1} C_{2}}{2 B \gamma}(b+\sqrt{\delta}), \quad a_{s}=-\frac{\varphi_{f} \tau_{s}}{C_{1}\left(\varphi_{s}-\varphi_{f}\right)} B, \quad \varphi_{s}=\frac{C_{1}}{2 \gamma}\left(b^{*}+\sqrt{\delta}\right)
$$


The relationships between the fast and slow parameters are given below,

Based on (13)-(15), we can see that

$$
\left\{\begin{array}{l}
T_{1} \sim T_{2} \sim \frac{\varepsilon}{B} t \rightarrow \infty . \\
T_{v}=\frac{\varepsilon}{B} * \frac{C_{2}}{\gamma}=\text { finite, } \quad \text { when } t \rightarrow \infty \\
\frac{\mathrm{d} T_{1}}{d t}=\frac{\mathrm{d} T_{2}}{d t}=\frac{\varepsilon}{B}
\end{array}\right.
$$

Under constant $\gamma$, the warming rate for the 2-box ocean will eventually approach that of the 1-box ocean (Eq. 5).

The fast and slow transient timescales $\tau_{f}$ and $\tau_{s}$ given in Eqs. (19)-(20) are roughly about five and 270 years, respectively, given the parameter $\gamma$ of $0.5 \mathrm{~W} / \mathrm{m}^{2} / \mathrm{K}, B$ of $1.5 \mathrm{~W} / \mathrm{m}^{2} / \mathrm{K}$ and the depths of 2-box ocean of 400 and $4000 \mathrm{~m}$. Since we consider a linearly increasing external forcing in this paper, it is the warming rate, instead of warming itself, that can reach the equilibrium. Therefore, $\tau_{f}$ and $\tau_{s}$ can be treated as the e-folding timescales of the warming rate for the upper and deep oceans, respectively. This is qualitatively consistent with fast and slow timescales for the temperature changes in a 2-layer ocean, under sudden constant external forcing (Gregory et al. 2015).

Figures 5a-c show the results of theoretical solutions (13)-(17). The deep-ocean heat uptake can slow down the surface warming. This is straightforward, and can be easily deduced from Eqs. (1) and 
(10). Under the same external forcing and climate feedback, the surface temperature increase in the 2box model is smaller in magnitude than that in the 1-box model. For example, at the end of the $200^{\text {th }}$ year, $T_{1}$ in the 2-box model is about $1.80^{\circ} \mathrm{C}$ (Fig. 5a), $15 \%$ smaller than that $\left(\sim 2.1^{\circ} \mathrm{C}\right)$ in the 1 -box model (Fig. 4a). Here, $\gamma$ is $0.5 \mathrm{~W} / \mathrm{m}^{2} / \mathrm{K}$ and $B$ is $1.5 \mathrm{~W} / \mathrm{m}^{2} / \mathrm{K}$. Under the linearly increasing forcing, in the long run (more than 1000 years), the 2-layer system can approach an "equilibrium" state, in terms of warming rate $\left(\frac{d T}{d t}\right)$ and vertical temperature gradient $\left(T_{v}\right)$ (Figs. 5b, c). The 2-layer ocean will eventually warm up at the same rate $\frac{\varepsilon}{B}$ (Fig. 5b), which is independent on $\gamma . T_{v}$ will eventually reach a constant $\frac{\varepsilon}{B} * \frac{C_{2}}{\gamma}$ (Fig. 5c), which is inversely proportional to $\gamma$.

It is obvious that the efficiency of vertical heat transport $\gamma$ affects the magnitude and timescale of the temperature change in each layer. It does not affect those of the whole ocean, since it only redistributes the heat in the vertical. A larger $\gamma$ will lead to a quicker and stronger warming in the deep ocean, at the cost of a slower and weaker warming in the upper ocean (dashed curves, Figs. 5a, b), which leads to a weaker vertical temperature gradient (dashed black, Fig. 5c). Note that a larger $\gamma$ can result in a weaker surface warming only at a short timescale. The surface warming under a larger $\gamma$ will eventually surpass that under a smaller $\gamma$, because the larger $\gamma$ can reduce the temperature stratification significantly, which in turn reduces the downward heat transport and results in an increasing surface warming. The theoretical solution (Eq. 21) shows that the equilibrium warming rates for both the surface and deep oceans depend only on the external heat rate $(\varepsilon)$ and the overall climate feedback $(B)$ of the system, regardless of the interior parameters of the ocean. The overall warming magnitude and warming rate for the whole ocean (figure not shown) would eventually approach those in the 1-box model, given the identical total ocean depth, the climate feedback in the two models and long enough time. Here, we see that under a constant $\gamma$, a decrease of the warming 
rate in the surface ocean will never occur. In other words, the surface ocean hiatus will never happen in this situation.

\subsection{Varying efficiency of vertical heat transport}

In reality, the surface ocean is usually warmed up faster than the deep ocean, leading to an enhanced vertical stratification at least during the transient period of global warming (Yang and Zhang 2008; Yang and Wang 2009). Although there is a lack of observational evidence supporting the proportional relationship between stratification and the efficiency of vertical heat transport in reality, we can study a varying efficiency in the simple conceptual model, to gain insight to its role in surface warming hiatus. Here, we assume a linear relationship between the efficiency of vertical heat transport and vertical temperature gradient as follows,

$$
\gamma=\gamma_{0}+\beta T_{v},
$$

where $\gamma_{0}$ is the reference efficiency from an unperturbed state (set to $0.5 \mathrm{~W} / \mathrm{m}^{2} / \mathrm{K}$ ). $\beta$ is changing rate of $\gamma$, related to $T_{v}$. A positive $\beta$ denotes a more (less) efficient vertical heat transport in response to an enhanced (weakened) stratification; and a negative $\beta$ denotes a less (more) efficient vertical heat transport in response to an enhanced (weakened) stratification. Combining Eq. (22) with Eqs. (10)-(12), the 2-layer system becomes a cubic system, and we can expect a third-order spline curve of the warming rate, with two turning points. We solve this system numerically.

It is expected that an enhanced efficiency of vertical heat transport would slow down the surface warming to some extent, which is shown in Figs. $5 \mathrm{~d}$ and e. For a strong positive $\beta$, the surface ocean warming rate will reduce slightly after the fast transient period (Fig. 5e). However, the warming rate 
will restore and increase to the control level during the slow evolution stage of the deep ocean (red curve, Fig. 5e). In the beginning, when the temperature change in the deep ocean is small, the stratification is enhanced significantly with time, leading to a higher efficiency of downward heat transport, and thus a slightly reduced warming rate in the upper ocean. In the later stage, after the warmup of the deep ocean, although the stratification is still being enhanced (red curve, Fig. 5f), the efficiency is reduced. The important implication is that the previously restored heat in the deep ocean will be released back to the upper ocean, enhancing the surface warming. In other words, the deep ocean loses its capability of storing heat, resulting in a quicker surface warming.

The consequence for a negative $\beta$, i.e., a weaker efficiency for a stronger stratification, is straightforward. The surface warming rate, vertical temperature gradient and surface climate will explode, that is, the runaway climate would become inevitable, which would occur much faster than expected. This situation is shown by the blue curves in Figs. $5 \mathrm{~d}$, e and $\mathrm{f}$, in which $\beta$ is set to -0.5 $\mathrm{W} / \mathrm{m}^{2} / \mathrm{K}^{2}$. We are not sure whether a negative $\beta$ would be possible in reality. Considering the vast ocean and the complex bio-geo-chemical and physical processes in the real ocean, one cannot exclude the possibility that a negative $\beta$ could occur.

\subsection{Varying climate feedback and efficiency of vertical heat transport}

If we consider both an enhanced negative feedback and an enhanced downward heat transport efficiency, the combined effect on the surface warming is roughly the linear superimposition of these two factors (blue curves, Fig. 6). The surface warming rate can be reduced significantly, as expected. However, the surface warming hiatus would not occur in several hundreds of years. Both effects can 
slow down the surface warming, but it is unlike to lead to a zero warming rate, i.e., the hiatus, under a linearly increasing external forcing.

Some studies suggested that the downward heat transport has contributed a great deal to the recent global warming hiatus. Watanabe et al. (2013) found ocean heat transport efficiency changes oppositely in general circulation models (GCMs) and in nature, namely, it is weakened in GCMs and strengthened in nature. The weakening tendency of $\gamma$ in GCMs is seen in the concomitant transient experiments, in which $\mathrm{CO}_{2}$ is increased at $1 \%$ per year, and also in individual models. These authors believed this can be the reason that GCMs tend to overestimate the surface warming trend. This is qualitatively consistent with our results with a negative $\beta$ (blue curve, Fig. 5e). England et al. (2014) also pointed out that anomalous winds can cause ocean energy redistribution, and thus induce the warming slowdown; however, rapid warming is expected to resume once the anomalous wind trends abate. This is in agreement with our results with a positive $\beta$ (red curve, Fig. 5). Although the triggering mechanisms are different in different studies and people tend to agree that the downward heat redistribution can slow down the surface warming rate, the hiatus induced by enhanced subsurface heat uptake cannot last long and the surface temperature will eventually climb up afterwards. The 2-box model is quite simple; nevertheless, it captures the essential mechanism, which is qualitatively consistent with that from more complex coupled models and observational studies.

\section{Four-box model with meridional overturning circulation}

To investigate the effect of ocean circulation on the surface warming, we need to use a 4-box model, the simplest setup to describe the meridional overturning circulation (MOC). The MOC plays an extremely important role in the heat exchange between the upper and deep oceans, between the 
low and high latitudes and between the two hemispheres (Broecker 1987; Talley 2013). The Atlantic

MOC (AMOC) is especially effective in energy re-distribution in both meridional and vertical directions. Chen and Tung (2018) showed that the decadal and interdecadal variation of GMST is mostly dominated by an inter-hemispheric dipole in the Atlantic basin, called the Atlantic MultiDecadal Oscillation (AMO), which also reflects the variation of the AMOC.

The 4-box model system includes a 2-box atmosphere as well as a 4-box ocean (Fig. 2c). The atmosphere is assumed to be always in quasi-equilibrium with the surface ocean. The ocean model is based on Stommel (1961), which was further developed (e.g., Marotzke 1990; Huang et al. 1992;

Nakamura et al. 1994; Tziperman et al. 1994; Marotzke and Stone 1995). In previous studies, we have used this 4-box model to investigate the Bjerknes compensation (BJC) in meridional heat transports (Yang et al. 2016). Detailed descriptions of the box model can also be found there. The temperature equations for the ocean boxes are

$$
\begin{gathered}
C_{1} \frac{d T_{1}}{d t}=\left(A_{1}-B_{1} T_{1}\right)+\chi\left(T_{2}-T_{1}\right)+q\left(T_{2}-T_{1}\right) \\
C_{2} \frac{d T_{2}}{d t}=\left(A_{2}-B_{2} T_{2}\right)-\chi\left(T_{2}-T_{1}\right)+q\left(T_{4}-T_{2}\right) \\
C_{3} \frac{d T_{3}}{d t}=q\left(T_{1}-T_{3}\right) \\
C_{4} \frac{d T_{4}}{d t}=q\left(T_{3}-T_{4}\right) \\
q=\kappa\left[\alpha_{T}\left(T_{2}-T_{1}\right)-\beta_{S}\left(S_{2}-S_{1}\right)\right]
\end{gathered}
$$

where $A_{1}$ and $A_{2}$ are net incoming radiation $\left(W^{-2}\right)$ in the extratropics and tropics, respectively; $B_{1}$ and $B_{2}$ are climate feedback parameters in the extratropics and tropics, respectively. $\chi$ is the efficiency of atmosphere heat transport. $C_{i}$ is the seawater heat capacity of each box. $q$ is the strength of the meridional mass transport, which is determined by both meridional temperature 
contrast $\left(T_{2}-T_{1}\right)$ and meridional salinity contrast $\left(S_{2}-S_{1}\right) . \kappa$ is a constant parameter that sets the reference flushing (turnover) timescale for the surface ocean box (units: $s^{-1}$ ); $\alpha_{T}$ and $\beta_{S}$ are the thermal and haline expansion coefficients of seawater, respectively. For simplicity, the formulae of salinity for each box are not shown here. Readers are referred to Yang et al. (2016) for details. The standard parameters used are listed in Table 1.

To test the effect of the AMOC strength on the surface warming rate, we simply add a coefficient $k$ in Eq. (27), that is,

$$
q=k * \kappa\left(\alpha_{T} T_{S}-\beta_{S} S_{S}\right)
$$

Here, $T_{s}=T_{2}-T_{1}$ and $S_{s}=S_{2}-S_{1}$. In this paper, $k$ is set to $1.5,1.0$, and 0.8 , respectively. A larger $k$ means a stronger AMOC.

We first conduct a control run to obtain the equilibrium state of the 4-box model. For the equilibrium state without external heating, the net TOA heat flux is zero, with the incoming radiation $A_{1}+A_{2}$ well balanced by the outgoing radiation $-\left(B_{1} T_{1}+B_{2} T_{2}\right)$. Using the parameters in Table 1 , the equilibrium $T_{1}=T_{3}=T_{4}=0.7^{\circ} \mathrm{C}, T_{2}=28.7^{\circ} \mathrm{C}$ and the equilibrium MOC is about $6.0 \mathrm{~Sv}$.

Applying the linear forcing (Eq. (2)) in both box-1 and box-2 models, we can see that the surface ocean warms up nearly linearly (solid curves, Fig. 7a), as expected. The deep ocean warms up slowly, lagging the surface warming by several decades (dashed curves, Fig. 7a), due to the slow downward heat transport carried out by the MOC. The MOC is marginally weakened ( $15 \%$ after 1000 years of heating) (black curve, Fig. 7c), because $T_{s}$ is only slightly reduced $\left(\sim 0.25^{\circ} \mathrm{C}\right)$ (black curve, Fig. 7d). The MOC change $(\Delta q)$ is mainly determined by $\Delta T_{s}$ because there is no salinity 
change $\left(\Delta S_{S}\right)$ in this experiment. The warming rate of the surface ocean reaches equilibrium quickly in about 50 years (solid curves, Fig. 7b).

Here, we emphasize that, under purely heating forcing, the MOC change is negligible in the 4box model. This was pointed out in our previous paper (Yang et al. 2016). Therefore, to explore the impact of the MOC change on surface ocean warming rate, we can modulate the MOC as suggested in Eq. (28). It is straightforward that a stronger (weaker) MOC will reduce (enhanced) the surface warming rate to some extent (Fig. 7b), provided that the same external heating is used. However, the equilibrium warming rate for the surface ocean appears to be independent from the MOC strength (Fig. 7b). This can be understood from Eqs. (23)-(24), which qualitatively gives $\left(C_{1} \frac{d T_{1}}{d t}+C_{2} \frac{d T_{2}}{d t}\right) \propto \varepsilon$ after the slow transient timescale $\tau_{s}$. Here, $\varepsilon$ is the external heating rate given in Eq. (2). The role of the MOC in surface warming rate is qualitatively consistent with that of the vertical heat mixing discussed in the 2-box model in section 2.2. Therefore, it is reasonable to conclude that the downward heat transport by the MOC would not result in a zero surface warming rate, i.e., the hiatus.

\section{We should keep in mind that in reality, under the external heating forcing, the global} temperature changes actually result from two factors: one is the pure radiative heating effect caused by GHGs change, and the other is the freshwater effect related to changes in precipitation, evaporation and sea-ice melting. Previous studies suggested that freshwater change due to global warming has a significant cooling effect, which can mitigate the global surface warming by as much as $\sim 30 \%$ (Wen et al. 2019). Under purely external heating, the GMST hiatus appears to be unlikely with the negligible change in the MOC, as shown in the 4-box model result (Fig. 7) and sensitivity experiments using a complex Earth system model (Wen et al. 2019). However, in response to the external heating, if the global hydrological cycle changes remarkably, so does the global MOC, the temporary warming hiatus would be possible (Yang et al. 2018; Wen et al. 2019). Whether or not the 
global hydrological change plays an important role in the GMST trend needs to be investigated indepth using Earth system models, which is beyond the scope of this paper.

\section{Conclusions and discussion}

Inspired by the heated debate on the recent warming hiatus, we investigated three factors that could potentially mitigate GMST warming: the climate feedback of Earth system, vertical heat mixing and global ocean MOC. The role of the climate feedback was studied using a 1-box EBM. It is shown that under the enhanced heating of GHGs, the GMST warming rate can be reduced if the global climate feedback becomes stronger. However, a zero warming rate, i.e., the warming hiatus, appears to be unlikely, unless the global overall climate feedback goes to negative infinity. We realize that even under a very strong negative feedback, its damping effect on the global warming takes a long time to come into play and the magnitude is limited. Regardless of its simplicity, the 1-box EBM tells us that fundamentally, the climate feedback alone would never lead to a short-time hiatus, as observed in the first decades of the 21 th century.

Under current global warming, the deep ocean, as an energy reservoir, is widely expected to curb the surface warming to some extent. Using a 2-box EBM, we found that the downward heat redistribution can indeed slow down the surface warming rate in the beginning; however, the hiatus induced by enhanced subsurface-ocean heat uptake cannot last long. Sooner or later, the previously stored heat in the deep ocean will be released back to the upper ocean, resulting in a quicker surface warming than that in the beginning. The 2-box model is simple; nevertheless, it exhibits the essential processes of the vertical heat transport and the deep ocean's roles in the global warming. Results from 
this simple model are qualitatively consistent with those from observational studies and complex coupled modelling studies.

MOC is well expected to store extra heat in the interior ocean. The AMOC is thought to play a key role, which has been explored in many studies using coupled climate models. Using a simple 4box model, we showed that the mechanism of AMOC in mitigating surface warming is similar to that of vertical heat transport. It is straightforward that a stronger AMOC can mitigate the surface warming rate to some extent. However, we also showed that the equilibrium warming rate for the surface ocean is independent of the AMOC strength. We conclude that the downward heat transport by the AMOC would not result in a hiatus.

We need to be aware that in the real world, GMST change would never be as stable as shown in these simple models. It can be affected by volcano eruptions and other important aerosols, sunspot activities, cloud amount and distribution. Decadal temperature change can be even stronger than the long-term trend (Liebmann et al. 2010), so is the decadal climate feedback. Therefore, it is likely that the recent hiatus has some link to a more negative decadal-changed climate feedback, as suggested in Zhou et al. (2016). SST pattern-induced low-cloud anomalies are substantially more negative than the long-term cloud feedback, and could have contributed to the period of reduced warming between 1998 and 2013 (Zhou et al. 2016).

In the box models, several assumptions are used, which are simple but without loss of generality. For example, in the 1-box model we assumed a linear increase of the negative feedback with the increase of GMST, to test whether a stiffening-up of damping effect of the climate feedback could possibly lead to a hiatus. We found that a zero warming rate is not plausible under the linearly increasing external heating. In the 2-box model, the vertical heat transfer efficiency was assumed to change linearly with vertical temperature gradient. Thus, we found that a slowdown of the surface 
ocean warming will be surely followed by an acceleration of surface warming. In the 4-box model, we tested the AMOC effect on the surface warming rate by adding a coefficient. We showed clearly that it is not a solution to curb the global warming by simply enhancing the MOC. The box models use several important parameters, such as the climate feedback, vertical heat transfer coefficient, the thicknesses of the upper and lower oceans, etc. We tested a wide range of values of these parameters, and they do not affect our conclusions in this paper.

Results from simple box models warn us that we should not be blinded by the short-term warming slowdown, as shown in the observations. The long-term trend of global warming cannot be undermined by the occurrence of a one-time, 15-year hiatus. The severity of climate change is closely tied to the total emissions due to anthropogenic activities since the Industrial Revolution, because the carbon dioxide is long lived in the atmosphere. Reducing the GHG emission appears to be the most feasible solution to prevent the Earth from becoming too warm for humans to live on.

Acknowledgement: This work is jointly supported by the National Nature Science Foundation of China (41725021, 91737204 and 41376007) and the National Key Research and Development Program of China (2016YFA0601802). 


\section{References}

Abramowitz M, Stegun IA eds (1964) Handbook of mathematical functions with formulas graphs mathematical tables. US Government printing office, 446-452.

Armour KC, Bitz CM, Roe GH (2013) Time-varying climate sensitivity from regional feedbacks. J Clim 26: 4518-4534.

Balmaseda MA, Mogensen K, Weaver AT (2013a) Evaluation of the ECMWF ocean reanalysis system ORAS4. Quarterly journal of the royal meteorological society 139: 1132-1161.

Balmaseda MA, Trenberth KE, Källén E (2013b) Distinctive climate signals in reanalysis of global ocean heat content. Geophys Res Lett 40: 1754-1759.

Bloch-Johnson J, Pierrehumbert RT, Abbot DS (2015) Feedback temperature dependence determines the risk of high warming. Geophys Res Lett 42: 4973-4980.

Bony S, Colman R, Kattsov VM, Allan RP, Bretherton CS, Dufresne JL, Hall A, Hallegatte S, Holland MM, Ingram W, Randall DA (2006) How well do we understand evaluate climate change feedback processes? J Clim 19: 3445-3482.

Broecker WS (1987) The biggest chill In Global Climate Change Linkages; Acid Rain Air Quality Stratospheric Ozone, Elsevier New York, 13-22.

Brown PT, Li W, Xie SP (2015) Regions of significant influence on unforced global mean surface air temperature variability in climate models. Journal of Geophysical Research: Atmospheres 120: 480-494.

Chen X, Tung KK (2014) Varying planetary heat sink led to global-warming slowdown acceleration. Science 345: 897-903.

Chen X, Tung KK (2018) Global surface warming enhanced by weak Atlantic overturning circulation. Nature 559: 387-391. 
Clement A, DiNezio P (2014) The tropical Pacific Ocean -- Back in the driver's seat? Science 343: 976-978.

Dai A, Fyfe JC, Xie SP, Dai X, (2015) Decadal modulation of global surface temperature by internal climate variability. Nature Climate Change 5: 555-559.

Easterling DR, Wehner MF (2009) Is the climate warming or cooling? Geophys Res Lett 36.

England MH, Mcgregor S, Spence P, Meehl GA, Timmermann A, Cai W et al (2014) Recent intensification of wind-driven circulation in the Pacific and the ongoing warming hiatus. Nature Climate Change 4: 222-227.

Geoffroy O, Saint-Martin D, Olivié DJ, Voldoire A, Bellon G, Tytéca S (2013) Transient climate response in a two-layer energy-balance model. Part I: Analytical solution parameter calibration using CMIP5 AOGCM experiments. J Clim 26: 1841-1857.

Gregory JM, Mitchell JF (1997) The climate response to CO2 of the Hadley Centre coupled AOGCM with and without flux adjustment. Geophys Res Lett 24: 1943-1946.

Gregory JM (2000) Vertical heat transports in the ocean and their effect on time-dependent climate change. Clim Dyn 16: 501-515.

Gregory JM, Ingram WJ, Palmer MA, Jones GS, Stott PA, Thorpe RB, Lowe JA, Johns TC, Williams KD (2004) A new method for diagnosing radiative forcing and climate sensitivity. Geophys Res Lett 31.

Gregory JM, Rews T, Good P (2015) The inconstancy of the transient climate response parameter under increasing CO2. Philosophical Transactions of the Royal Society A: Mathematical Physical and Engineering Sciences 373.

Hansen J, Johnson D, Lacis A, Lebedeff S, Lee P, Rind D, Russell G (1981) Climate impact of increasing atmospheric Carbon Dioxide. Science 213: 957-966. 
Held IM, Winton M, Takahashi K, Delworth T, Zeng F, Vallis GK (2010) Probing the fast and slow components of global warming by returning abruptly to preindustrial forcing. J Clim 23: 24182427.

Huang RX, Luyten JR, Stommel HM (1992) Multiple equilibrium states in combined thermal and saline circulation. J Phys Oceanogr 22: 231-246.

IPCC (2013) Climate Change 2013: The Physical Science Basis. Cambridge University Press 1535pp.

Jones PD, Lister DH, Osborn TJ, Harpham C, Salmon M, Morice CP (2012) Hemispheric and largescale land surface air temperature variations: an extensive revision and an update to 2010. Journal of Geophysical Research, doi: 10.1029/2011JD017139.

Kaufmann RK, Kauppi H, Mann ML, Stock JH (2011) Reconciling anthropogenic climate change with observed temperature 1998-2008. Proc Natl Acad Sci 108: 11790-11793.

Kühn T, Partanen AI, Laakso A, Lu Z, Bergman T, Mikkonen S, Kokkola H, Korhonen H, Räisänen P, Streets DG, Romakkaniemi S (2014) Climate impacts of changing aerosol emissions since 1996. Geophys Res Lett 41: 4711-4718.

Knight J, Kennedy J, Folland C, Harris G, Jones GS, Palmer M, Parker D, Scaife A, Stott P (2009) Global oceans: Do global temperature trends over the last decade falsify climate predictions? Bull Am Meteorol Soc 90: 56-57.

Kosaka Y, Xie SP (2013) Recent global-warming hiatus tied to equatorial Pacific surface cooling. Nature 501: 403-407.

Lee SK, Park W, Baringer MO, Gordon AL, Huber B, Liu Y (2015) Pacific origin of the abrupt increase in Indian ocean heat content during the warming hiatus. Nature Geoscience 8: 445-449.

Lewandowsky S, Risbey JS, Oreskes N (2016) The "pause" in global warming: Turning a routine fluctuation into a problem for science. Bull Am Meteorol Soc 97: 723-733.

Liebmann B, Dole RM, Jones C, Bladé I, Allured D (2010) Influence of choice of time period on global surface temperature trend estimates. Bull Am Meteorol Soc 91: 1485-1492. 
Liu W, Xie SP, Lu J (2016) Tracking ocean heat uptake during the surface warming hiatus. Nature Communications 7: 1-9.

Loeb NG, Lyman JM, Johnson GC, Allan RP, Doelling DR, Wong T, Soden BJ, Stephens GL (2012) Observed changes in top-of-the-atmosphere radiation and upper-ocean heating consistent within uncertainty. Nature Geoscience 5: 110-113.

Manabe S, Bryan K (1985) CO2-induced change in a coupled ocean-atmosphere model and its paleoclimatic implications. J Geophys Res 90: 11689-11707.

Marotzke J (1990) Instabilities and multiple equilibria of the thermohaline circulation. Ph.D thesis Ber Inst Meeresk Kiel, Germany, 126 pp.

Marotzke J, Stone P (1995) Atmospheric transports the thermohaline circulation and flux adjustments in a simple coupled model. J Phys Oceanogr 25: 1350-1364.

Meehl GA, Arblaster JM, Fasullo JT, Hu A, Trenberth KE (2011) Model-based evidence of deepocean heat uptake during surface-temperature hiatus periods. Nature Climate Change 1: 360-364.

Meehl GA, Coauthors (2013) Climate change projections in CESM1 (CAM5) compared to CCSM4. J Clim 26: 6287- 6308.

Morice CP, Kennedy JJ, Rayner NA, Jones PD (2012) Quantifying uncertainties in global and regional temperature change using an ensemble of observational estimates: The HadCRUT4 dataset. Journal of Geophysical Research 117: D08101. https://doi.org/10.1029/2011JD017187.

Nakamura M, Stone PH, Marotzke J (1994) Destabilization of the thermohaline circulation by atmospheric eddy transports. J Clim 7: 1870-1882.

Nieves V, Willis JK, Patzert WC (2015) Recent hiatus caused by decadal shift in Indo-Pacific heating. Science 349: 532-535.

Raper SCB, Gregory JM, Stouffer RJ (2002) The role of climate sensitivity and ocean heat uptake on AOGCM transient temperature response. J Clim 15: 124-130. 
Rhein M et al (2013) Observations: Ocean in Climate Change 2013: The Physical Science Basis.

$$
\text { Cambridge Univ Press, 255-316. }
$$

Roe GH, Armour KC (2011) How sensitive is climate sensitivity? Geophys Res Lett 38: L14708. doi: 10.1029/2011GL047913.

Rugenstein M, Bloch-Johnson J, Gregory JM, Mauritsen T, Li C, Frölicher TL, Paynter D, Danabasoglu G, Yang S, Dufresne JL (2020) Equilibrium climate sensitivity estimated by equilibrating climate models. Geophys Res Lett 47: p.e2019GL083898.

Santer BD, Bonfils C, Painter JF, Zelinka MD, Mears C, Solomon S, Schmidt GA, Fyfe JC, Cole JN, Nazarenko L, Taylor KE (2014) Volcanic contribution to decadal changes in tropospheric temperature. Nature Geoscience 7: 185-189.

Schmidt GA, Shindell DT, Tsigaridis K (2014) Reconciling warming trends. Nature Geoscience 7: $158-160$.

Soden BJ, Held IM (2006) An assessment of climate feedbacks in coupled ocean-atmosphere models. J Clim 19: 3354-3360.

Solomon S, Rosenlof KH, Portmann RW, et al (2010) Contributions of stratospheric water vapor to decadal changes in the rate of global warming. Science 327: 1219-1223. doi:10.1126/science 1182488.

Stommel H (1961) Thermohaline convection with two stable regimes of flow. Tellus 13: 224-230.

Talley LD (2013) Closure of the global overturning circulation through the Indian Pacific and Southern Oceans: Schematics and transports. Oceanography 26: 80-97.

Trenberth KE (2009) An imperative for adapting to climate change: Tracking Earth's global energy. Curr Opin Environ Sustain 1: 19-27.

Trenberth KE, Fasullo JT (2013) An apparent hiatus in global warming? Earths Future 1: 19-32. Tung KK, Chen X (2018) Understanding the recent global surface warming slowdown: a review. Climate 6: 82pp 
Tziperman E, Toggweiler JR, Feliks Y, Bryan K (1994) Instability of the thermohaline circulation with respect to mixed boundary conditions: Is it really a problem for realistic models. J Phys Oceanogr 24: 217-232.

Watanabe M, Kamae Y, Yoshimori M, Oka A, Sato M, Ishii M et al (2013) Strengthening of ocean heat uptake efficiency associated with the recent climate hiatus. Geophys Res Lett 40: 31753179.

Wen Q, Yao J, Doos K, Yang H (2018) Decoding hosing and heating effects on global temperature and meridional circulations in a warming climate. J Clim 31: 9605-9623. Doi: 10.1075/JCLI-D18-0297.1.

Winton M, Takahashi K, Held IM (2010) Importance of ocean heat uptake efficacy to transient climate change. J Clim 23: 2333-2344.

Xie SP, Kosaka Y, Okumura YM (2016) Distinct energy budgets for anthropogenic and natural changes during global warming hiatus. Nature Geosci 9: 29-33.

Yan XH, Boyer T, Trenberth K, Karl TR, Xie SP, Nieves V, Tung KK, Roemmich D (2016) The global warming hiatus: Slowdown or redistribution? Earth's Future 4: 472-482.

Yang H, Zhang Q (2008) Anatomizing the ocean role in ENSO changes under global warming. J Clim 21: 6539-6555. doi: 10.1175/2008JCLI2324.1.

Yang H, Wang F (2009) Revisiting the thermocline depth in the equatorial Pacific. J Clim 22: 38563863.

Yang H, Zhao Y, Liu Z (2016) Understanding Bjerknes compensation in atmosphere and ocean heat transports using a coupled box model. J Clim 29: 2145-2160. doi: 10.1175/JCLI-D-15-0281.1.

Yang Q, Zhao Y, Wen Q, Yao J, Yang H (2018) Understanding Bjerknes compensation in meridional heat transports and the role of freshwater in a warming climate. J Clim 31: 4791-4806. doi: 10.1175/JCLI-D-17-0587.1. 
636

637

638

639

640

641

642

643

Yoshimori M, Masahiro, Watanabe et al (2016) A review of progress towards understanding the transient global mean surface temperature response to radiative perturbation. Progress in Earth and Planetary Science 3.

Zhou C, Zelinka MD, Klein SA (2016) Impact of decadal cloud variations on the Earth's energy budget. Nature Geoscience 9: 871-874.

Zhou T, Chen X (2015) Uncertainty in the $2^{\circ} \mathrm{C}$ warming threshold related to climate sensitivity and climate feedback. Journal of Meteorological Research 29: 884-895. 
Table 1 Parameters used in the 4-box model.

\begin{tabular}{ccc}
\hline Symbol & Physical meaning & Value \\
\hline $\mathrm{A}_{1}, \mathrm{~A}_{2}$ & Net incoming radiative at box 1 and 2 & $-40,90 \mathrm{~W} \mathrm{~m}^{-2}$ \\
& Local climate feedback parameter in & \\
$\mathrm{B}_{1}, \mathrm{~B}_{2}$ & box 1 and box 2 & $1.7,1.7 \mathrm{~W} \mathrm{~m}^{-2} \mathrm{~K}^{-1}$ \\
$\mathrm{C}_{1}, \mathrm{C}_{2}$ & Seawater heat capacity for 4 boxes & {$[1.6,1.6,16,16] \times 10^{8} \mathrm{~J}$} \\
$\mathrm{C}_{3}, \mathrm{C}_{4}$ & Atmosphere heat transport efficiency & $1.3 \mathrm{~W} \mathrm{~m}^{-2} \mathrm{~K}^{-1}$ \\
$\chi$ & Advective timescale coefficient & $1.2 \times 10^{-7} \mathrm{~s}^{-1}$ \\
$\kappa$ & & \\
$\alpha_{\mathrm{T}}$ & Thermal expansion coefficient & $2.5 \times 10^{-4} \mathrm{~K}^{-1}$ \\
$\beta_{\mathrm{S}}$ & Haline contraction coefficient & $7.5 \times 10^{-4} \mathrm{psu}^{-1}$ \\
\hline
\end{tabular}




\section{Figure Captions}

Figure 1 Time series of observed global mean surface temperature (GMST) (black; units: ${ }^{\circ} \mathrm{C}$ ), global mean land surface temperature (red) and $\mathrm{CO}_{2}$ concentration (purple; units: ppm). For temperature, the climatological mean state of 1960-1990 is removed. Short blue lines show the linear trend of GMST in several different periods. Dashed vertical lines denote four serious volcanic events, occurred at Santa Maria in 1902, Agung in 1963, El Chichon in 1982, and Pinatubo in 1991, respectively. Dashed purple line shows the linear trend of $\mathrm{CO}_{2}$ concentration. The surface temperature data is from the HadCRUT4 (Jones et al. 2012; Morice et al. 2012), downloaded at https://crudata.uea.ac.uk/cru/data/temperature/. The $\mathrm{CO}_{2}$ data is from the station at Mauna Loa of Hawaii, downloaded at https://gml.noaa.gov/ccgg/trends/.

Figure 2 Schematic diagrams of box models: (a) 1-box ocean model, (b) 2-box ocean model and (c) 4-box ocean model. In all box models, the net radiation flux at the top of atmosphere (TOA) is $F+E$, each shown by an orange solid arrow. The ocean surface heat flux is denoted by the blue solid arrows. In (b) and (c), the yellow solid arrow represents the vertical heat transport in ocean interior. In (c), ocean boxes are denoted by (1), (2), (3), and (4). Boxes 2 and 4 represent the upper and lower layers of the tropical ocean; boxes 1 and 3, of the subpolar ocean. Solid grey arrow in ocean represents the Atlantic meridional overturning circulation (AMOC). Solid yellow and grey arrows in atmosphere represent the meridional atmosphere and ocean heat transports, respectively.

Figure 3 Temporal change of the linear radiative forcing imposed onto the energy balance model. The forcing increases at a rate of $0.016 \mathrm{~W} / \mathrm{m}^{2}$ per year. 
Figure 4 Temporal changes of sea-surface temperature (SST; units: ${ }^{\circ} \mathrm{C}$; left panels) and warming rate (units: ${ }^{\circ} \mathrm{C} / 100$-year; right panels) in 1-box model. Top panels are for constant climate feedback ( $B$; units: $\mathrm{W} / \mathrm{m}^{2} / \mathrm{K}$ ), and $B$ is set to be 1.0 (blue), 1.5 (black) or 2.0 (red), respectively. Bottom panels are for varying $B$, where $B$ decreases (blue) or increases (red) with SST at a rate of -1.0 or $-0.5(+1.0$ or +0.5$) \mathrm{W} / \mathrm{m}^{2} / \mathrm{K}^{2}$, and the black line is for the control case with constant $B(1.5$ $\left.\mathrm{W} / \mathrm{m}^{2} / \mathrm{K}\right)$.

Figure 5 Temporal changes of ocean temperature (units: ${ }^{\circ} \mathrm{C}$; left panels), warming rate (units: ${ }^{\circ} \mathrm{C} / 100$-year; middle panels) and ocean stratification ( $T_{v}$; units: ${ }^{\circ} \mathrm{C}$; right panels) in 2-box model. In (a)-(b), red curves are for upper ocean, and blue curves, for lower ocean. In (a)-(c) solid (dashed) curves represent the case when $\gamma=0.5(1.5) \mathrm{W} / \mathrm{m}^{2} / \mathrm{K}$. In (d)-(e), only SST changes are plotted. In (d)-(f), blue (red) curve is for the case when $\gamma$ decreases (increases) with $T_{v}$ at a rate of $-0.5(+1.0) \mathrm{W} / \mathrm{m}^{2} / \mathrm{K}^{2}$, and black curve is for the control case with constant $\gamma$ (i.e., $\beta=0$ ).

Figure 6 Same as Figs. 5d-f, but with both enhanced negative climate feedback and vertical heat transport considered simultaneously in the 2-box model. Black and red curves are the same as those in Figs. 5d-f. Blue curve is for the case with enhanced negative feedback $(\alpha=1)$ and vertical heat transport $(\beta=1)$.

Figure 7 Temporal changes of (a) ocean temperature, (b) warming rate, (c) strength of AMOC (units: $\left.\mathrm{Sv}, 1 \mathrm{~Sv}=10^{6} \mathrm{~m}^{3} \mathrm{~s}^{-1}\right)$, and (d) meridional temperature gradient $\left(T_{2}-T_{1}\right)$ in 4-box model. In (a)-(b), solid curves are for upper ocean $\left(T_{1}+T_{2}\right)$, and dashed curves, for lower ocean $\left(T_{3}+\right.$ $\left.T_{4}\right)$. In (a)-(d), black is for the control case $(k=1)$; red, for the case with an enhanced AMOC $(k=1.5)$ and blue, for the case with a weakened AMOC $(k=0.8)$. 


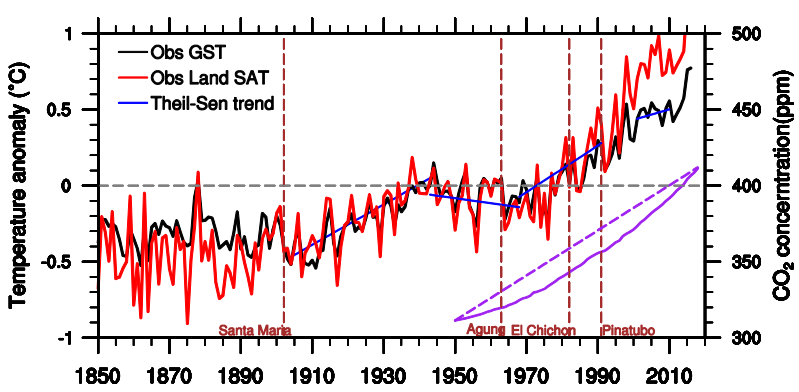

Figure 1 Time series of observed global mean surface temperature (GMST) (black; units: ${ }^{\circ} \mathrm{C}$ ), global mean land surface temperature (red) and $\mathrm{CO}_{2}$ concentration (purple; units: ppm). For temperature, the climatological mean state of 1960-1990 is removed. Short blue lines show the linear trend of GMST in several different periods. Dashed vertical lines denote four serious volcanic events, occurred at Santa Maria in 1902, Agung in 1963, El Chichon in 1982, and Pinatubo in 1991, respectively. Dashed purple line shows the linear trend of $\mathrm{CO}_{2}$ concentration. The surface temperature data is from the HadCRUT4 (Jones et al. 2012; Morice et al. 2012), downloaded at https://crudata.uea.ac.uk/cru/data/temperature/. The $\mathrm{CO}_{2}$ data is from the station at Mauna Loa of Hawaii, downloaded at https://gml.noaa.gov/ccgg/trends/. 
(a) $1-$ Box

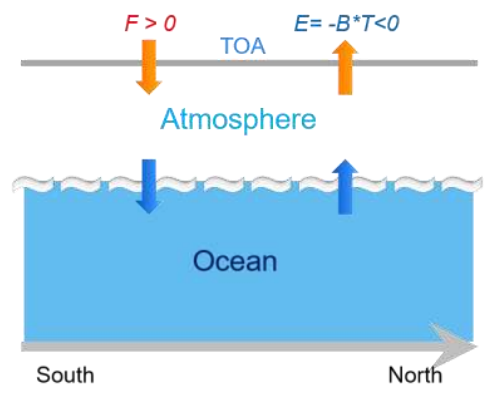

(b) 2-Box

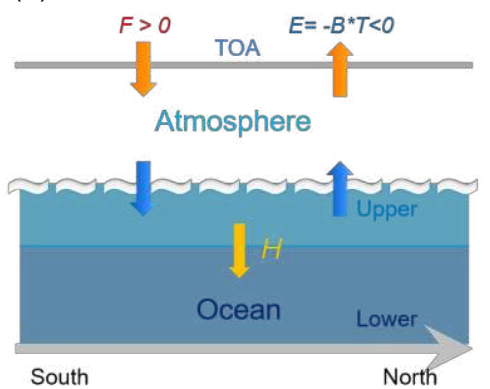

(c) 4-Box

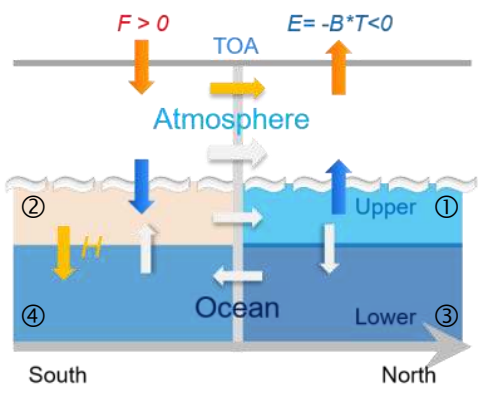

Figure 2 Schematic diagrams of box models: (a) 1-box ocean model, (b) 2-box ocean model and (c) 4-box ocean model. In all box models, the net radiation flux at the top of atmosphere (TOA) is $F+E$, each shown by an orange solid arrow. The ocean surface heat flux is denoted by the blue solid arrows. In (b) and (c), the yellow solid arrow represents the vertical heat transport in ocean interior. In (c), ocean boxes are denoted by (1), (2), (3), and (4). Boxes 2 and 4 represent the upper and lower layers of the tropical ocean; boxes 1 and 3, of the subpolar ocean. Solid grey arrow in ocean represents the Atlantic meridional overturning circulation (AMOC). Solid yellow and grey arrows in atmosphere represent the meridional atmosphere and ocean heat transports, respectively. 


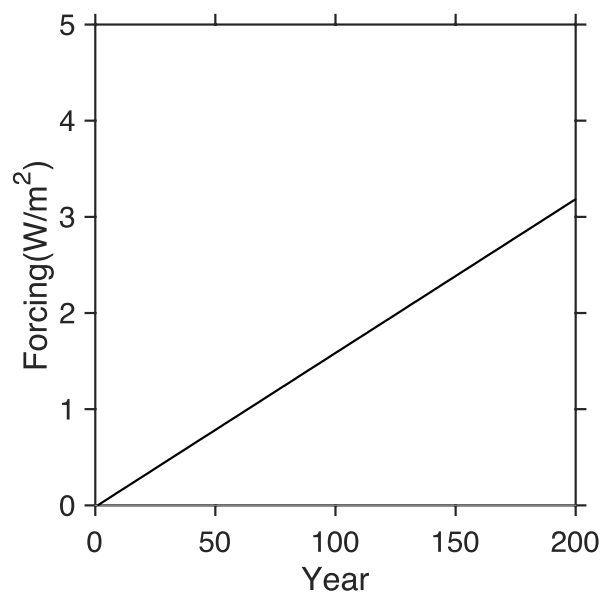

Figure 3 Temporal change of the linear radiative forcing imposed onto the energy balance model. The forcing increases at a rate of $0.016 \mathrm{~W} / \mathrm{m}^{2}$ per year. 

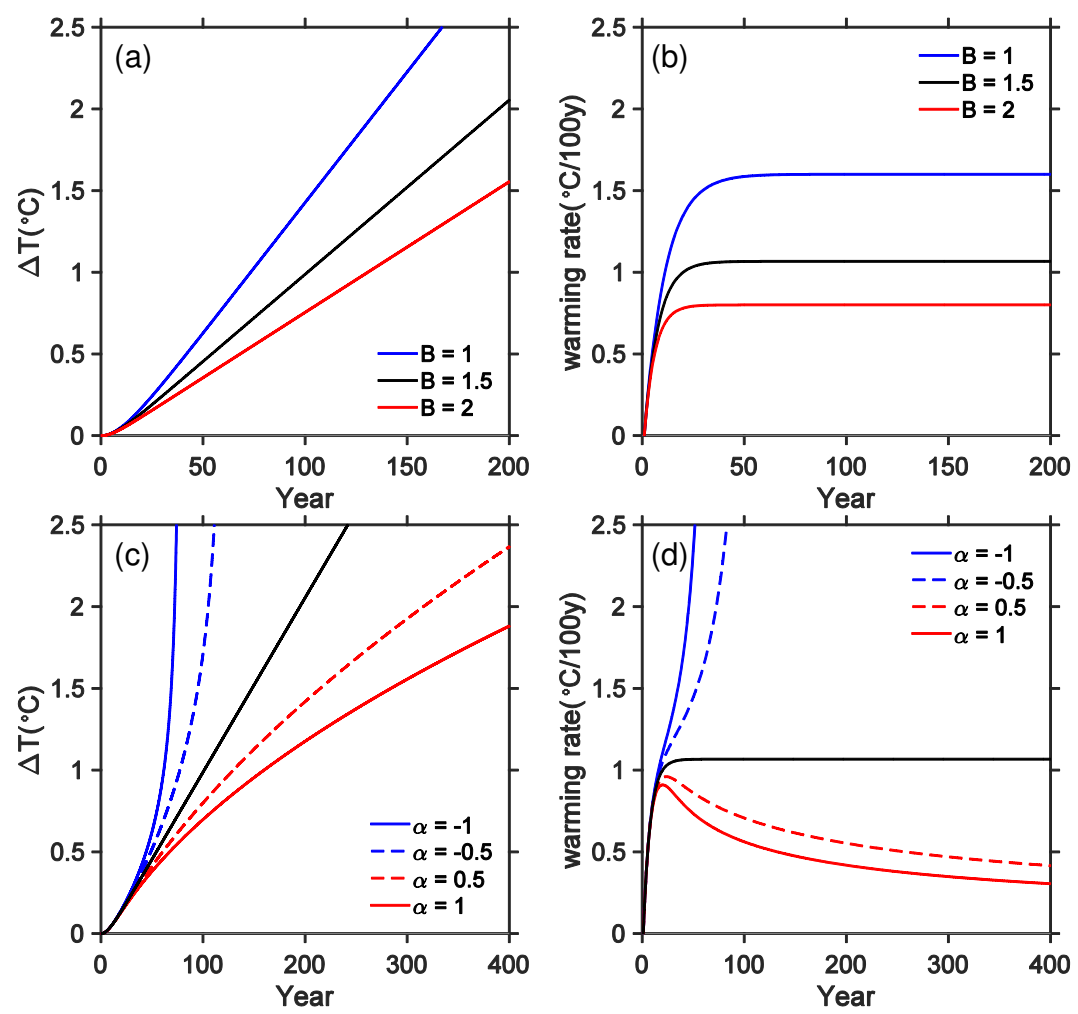

Figure 4 Temporal changes of sea-surface temperature (SST; units: ${ }^{\circ} \mathrm{C}$; left panels) and warming rate (units: ${ }^{\circ} \mathrm{C} / 100$-year; right panels) in 1-box model. Top panels are for constant climate feedback ( $B$; units: $\mathrm{W} / \mathrm{m}^{2} / \mathrm{K}$ ), and $B$ is set to be 1.0 (blue), 1.5 (black) or 2.0 (red), respectively. Bottom panels are for varying $B$, where $B$ decreases (blue) or increases (red) with SST at a rate of -1.0 or $0.5(+1.0$ or +0.5$) \mathrm{W} / \mathrm{m}^{2} / \mathrm{K}^{2}$, and the black line is for the control case with constant $B\left(1.5 \mathrm{~W} / \mathrm{m}^{2} / \mathrm{K}\right)$. 

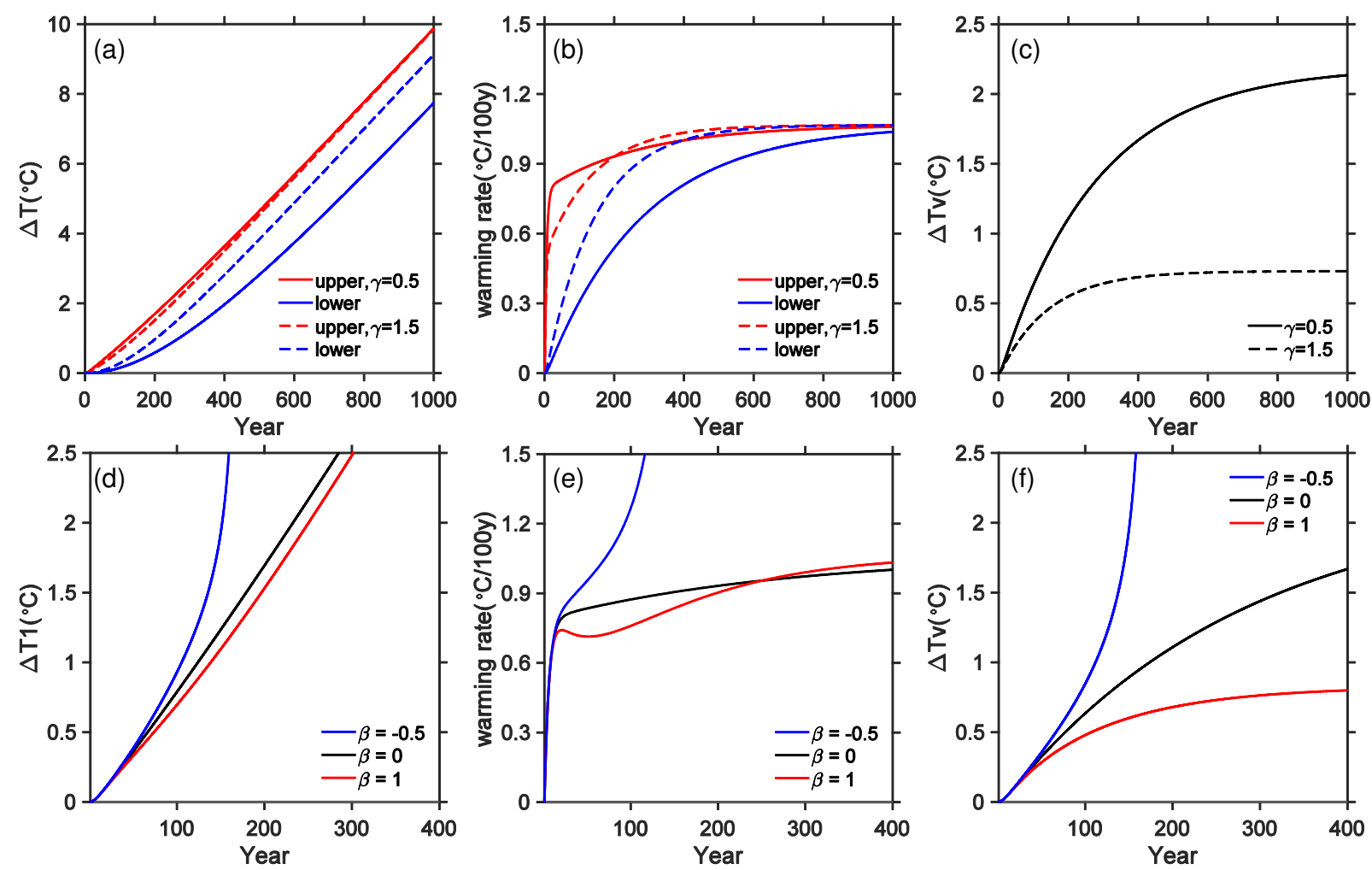

Figure 5 Temporal changes of ocean temperature (units: ${ }^{\circ} \mathrm{C}$; left panels), warming rate (units: ${ }^{\circ} \mathrm{C} / 100$-year; middle panels) and ocean stratification ( $T_{v}$; units: ${ }^{\circ} \mathrm{C}$; right panels) in 2-box model. In (a)-(b), red curves are for upper ocean, and blue curves, for lower ocean. In (a)-(c) solid (dashed) curves represent the case when $\gamma=0.5(1.5) \mathrm{W} / \mathrm{m}^{2} / \mathrm{K}$. In (d)-(e), only SST changes are plotted. In (d)-(f), blue (red) curve is for the case when $\gamma$ decreases (increases) with $T_{v}$ at a rate of $-0.5(+1.0)$ $\mathrm{W} / \mathrm{m}^{2} / \mathrm{K}^{2}$, and black curve is for the control case with constant $\gamma$ (i.e., $\beta=0$ ). 

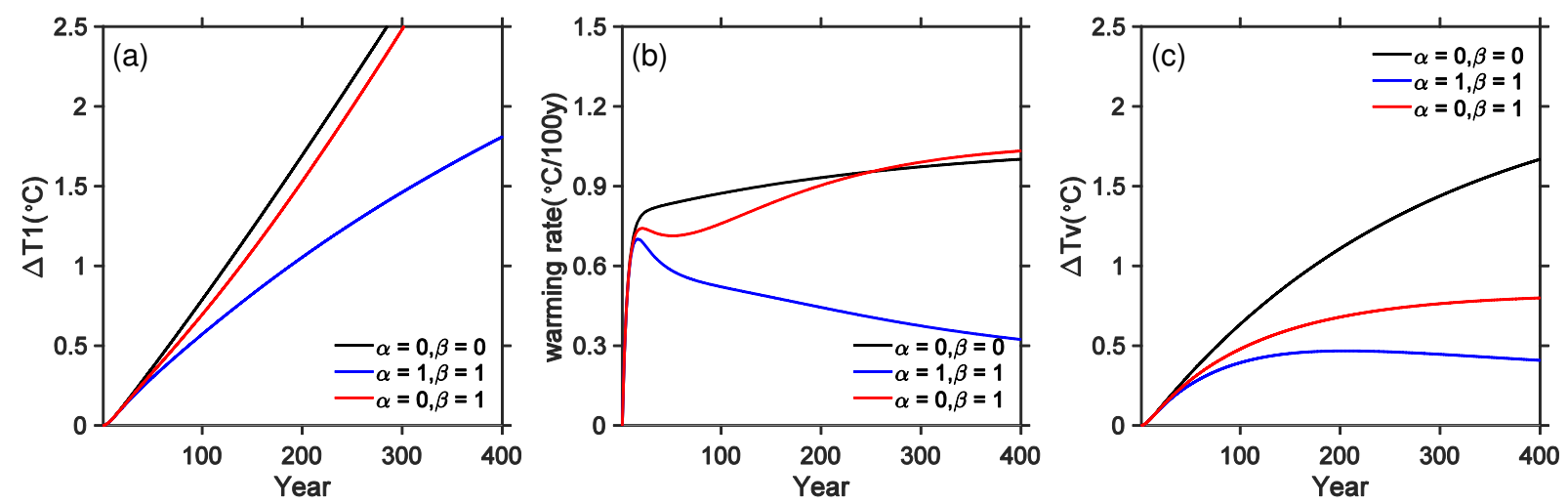

Figure 6 Same as Figs. 5d-f, but with both enhanced negative climate feedback and vertical heat transport considered simultaneously in the 2-box model. Black and red curves are the same as those in Figs. 5d-f. Blue curve is for the case with enhanced negative feedback $(\alpha=1)$ and vertical heat transport $(\beta=1)$. 

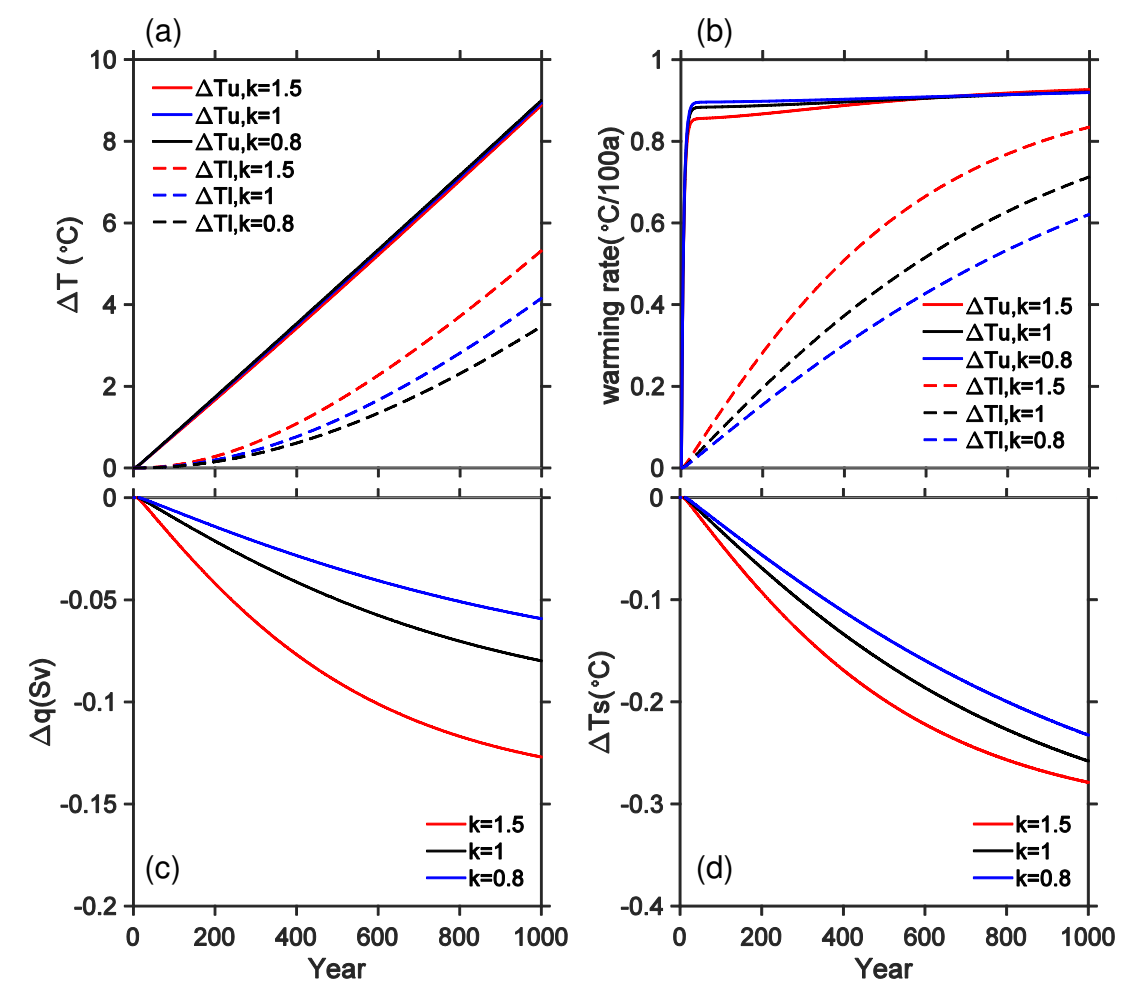

Figure 7 Temporal changes of (a) ocean temperature, (b) warming rate, (c) strength of AMOC (units: $\mathrm{Sv}, 1 \mathrm{~Sv}=10^{6} \mathrm{~m}^{3} \mathrm{~s}^{-1}$ ), and (d) meridional temperature gradient $\left(T_{2}-T_{1}\right)$ in 4-box model. In (a)-(b), solid curves are for upper ocean $\left(T_{1}+T_{2}\right)$, and dashed curves, for lower ocean $\left(T_{3}+T_{4}\right)$. In (a)-(d), black is for the control case $(k=1)$; red, for the case with an enhanced AMOC $(k=1.5)$ and blue, for the case with a weakened AMOC $(k=0.8)$. 